\title{
La exposición ambiental a insecticidas piretroides se asoció con mayor riesgo de mortalidad en la población adulta general de los EE.UU.
}

Environmental exposure to pyrethroid Insecticides was associated with higher risk of mortality in the general US adult

population

\section{Comentado de:}

Bao W, et al. Association Between Exposure to Pyrethroid Insecticides and Risk of All-Cause and Cause-Specific Mortality in the General US Adult Population. JAMA Intern Med. 2019;180(3):367-374. PMID: 31886824 ${ }^{1}$

\section{Importancia}

Se ha informado de una exposición generalizada a los insecticidas piretroides entre la población general en los EE.UU. y en todo el mundo. Sin embargo, se sabe poco sobre la asociación de la exposición a los piretroides con los resultados de salud a largo plazo en adultos.

\section{Objetivo}

Examinar la asociación de la exposición a piretroides con la mortalidad por todas las causas y por causas específicas en adultos en los EE.UU.

\section{Diseño, lugar y participantes}

La cohorte representativa a nivel nacional incluyó a 2.116 adultos de 20 años o más que participaron en la Encuesta nacional de salud y nutrición de EE.UU. (NHANES, por sus iniciales en inglés), realizada entre 1999 y 2002, y que proporcionaron muestras de orina para las mediciones de metabolitos piretroides. Los participantes se vincularon con los datos de mortalidad desde la fecha de la encuesta hasta el 31 de diciembre de 2015. Los datos se analizaron entre mayo y agosto de 2019.

\section{Exposición}

Los niveles urinarios de ácido 3-fenoxibenzoico, un metabolito piretroide general y biomarcador de uso común para la exposición a piretroides, se determinaron mediante el uso de cromatografía líquida de alto rendimiento junto con ionización química por electropulverización y espectrometría de masas en tándem.

\section{Desenlaces y medidas principales}

Mortalidad por todas las causas, enfermedad cardiovascular y cáncer.

\section{Resultados}

Este estudio de cohorte de 2.116 adultos comprendió a 1.145 mujeres (proporción ponderada, 51,6\%) y 971 hombres $(48,4 \%)$ con una edad media ponderada (desvío estándar) de 42,6 $(0,5)$ años; 958 participantes $(68,4 \%)$ eran de ascendencia blanca no hispana, $646(14,7 \%)$ de ascendencia hispana, 419 (11,3\%) de ascendencia negra no hispana, y $93(5,6 \%)$ de otra ascendencia. Durante una mediana de 14,4 años (rango, 0,1 a 16,8 años) de observación, se produjeron 246 muertes, incluidas 41 asociadas con enfermedades cardiovasculares y 52 asociadas con cáncer. Los participantes con niveles más altos de ácido 3-fenoxibenzoico en la orina tuvieron un mayor riesgo de muerte durante el período de seguimiento, con la ocurrencia del evento en $8,5 \%(75 / 709)$, $10,2 \%(81 / 701)$ y $11,9 \%(90 / 706)$ de participantes en terciles crecientes de niveles urinarios de ácido 3-fenoxibenzoico. Después del ajuste por edad, sexo, raza/etnia, estado socioeconómico, factores dietéticos y de estilo de vida, índice de masa corporal y niveles de creatinina urinaria, las razones de riesgo de mortalidad por todas las causas, mortalidad por enfermedad cardiovascular y mortalidad por cáncer entre los participantes con el tercil más alto en comparación con aquellos con el tercil más bajo de los niveles urinarios de ácido 3-fenoxibenzoico fueron 1,56 (Intervalo de Confianza [IC] del 95\%, 1,08 a 2,26), 3,00 (IC 95\%, 1,02 a 8,80 ) y 0,91 (IC $95 \%, 0,31$ a 2,72), respectivamente.

\section{Conclusiones}

En esta muestra representativa a nivel nacional de adultos de los EE.UU., la exposición ambiental a los insecticidas piretroides se asoció con un mayor riesgo de mortalidad por todas las causas y enfermedades cardiovasculares. Se necesitan más estudios para replicar los hallazgos y determinar los mecanismos subyacentes.

Fuente de financiamiento/Conflicto de interés de los autores: El Dr. Lehmler informó haber recibido subvenciones del Instituto Nacional de Ciencias de Salud Ambiental y los Institutos Nacionales de Salud de los EE.UU. durante la realización del estudio.

\section{Comentario}

Existe actualmente un interés creciente por estudiar los orígenes o la base fetal de las enfermedades del adulto (concepto conocido como DOHaD, por las iniciales en inglés de developmental origins of health and disease) teniendo en cuenta que muchas enfermedades crónicas podrían tener su inicio en etapas tempranas de la vida. Los resultados de este estudio muestran una fuerte asociación entre la exposición ambiental a los insecticidas piretroides y un mayor riesgo de mortalidad por todas las causas y en especial, por enfermedades cardiovasculares.

Si bien no se observó una diferencia significativa entre la exposición a insecticidas piretroides y la mortalidad por cáncer, la falta de significancia estadística con un grado tan amplio de imprecisión (amplitud del intervalo de confianza) implica la necesidad de realizar nuevos estudios, ya que esta ausencia de evidencia no constituye evidencia de ausencia de asociación entre ambas variables.

Una característica del efecto de los plaguicidas es que éstos pueden observarse a largo plazo, ya que si bien el daño se produce en general en períodos críticos del desarrollo, los efectos patológicos pueden manifestarse en ausencia evidente del factor de exposición o en un lapso de tiempo alejado del mismo, lo que dificulta establecer una asociación directa entre 
la exposición y el evento. Otra causa de las dificultades de cuantificar el efecto de los piretroides es la probable exposición simultánea a otros insecticidas, conocidos o no por la población expuesta. En este contexto, esta cohorte con un muestreo probabilístico y multietápico, con un seguimiento de 20 años, resulta el diseño más robusto para obtener información válida sobre los efectos tardíos de exposiciones tempranas a tóxicos ambientales.

Este estudio refuerza la importancia de incorporar la problemática de cuantificar los efectos cuando la exposición de la población es generalizada y provee argumentos para discutir el efecto perjudicial de los piretroides y su uso extendido en los domicilios, que fue evidenciado también en Argentina, por lo que podría ser considerado como un problema de Salud Pública ${ }^{2}$.

\section{Conclusiones de las comentadoras}

Teniendo en cuenta la elevada exposición a plaguicidas que presenta la población en Argentina, el nuevo conocimiento generado en este estudio nos brinda la oportunidad de repensar la importancia de regular el uso de plaguicidas domésticos a nivel local.

Analía Ferloni [ Departamento de Investigación, Programa de Investigación en Salud Ambiental, Hospital Italiano de Buenos Aires; Epidemiología, Departamento de Calidad., Hospital Italiano de Buenos Aires. analia.ferloni@hospitalitaliano.org.ar ]

Valeria Aliperti [ Departamento de Investigación, Programa de Investigación en Salud Ambiental, Hospital Italiano de Buenos Aires; Epidemiología, Departamento de Calidad., Hospital Italiano de Buenos Aires. valeria.aliperti@hospitalitaliano.org.ar ]

Ferloni A, Aliperti V. La exposición ambiental a insecticidas piretroides se asoció con mayor riesgo de mortalidad en la población adulta general de los EE.UU. . Evid Actual Pract Ambul. 2020;23(3):e002086. Comentado de: Bao W, et al. Association Between Exposure to Pyrethroid Insecticides and Risk of All-Cause and Cause-Specific Mortality in the General US Adult Population. JAMA Intern Med. 2019;180(3):367-374. PMID: 31886824

\section{Referencias}

1. Bao W, Liu B, Simonsen DW, et al. Association Between Exposure to Pyrethroid Insecticides and Risk of All-Cause and Cause-Specific Mortality in the General US Adult Population. JAMA Intern Med. 2019;180(3):367-374. Available from: 10.1001/jamainternmed.2019.6019.

2. Argentina. Ministerio de Salud de la Nación. Secretaría de Ambiente y Desarrollo Sustentable. Diagnóstico sobre el uso y manejo de plaguicidas de uso doméstico. Estudio colaborativo multicéntrico. ; 2007. Available from: https://www.yumpu.com/es/document/view/23097476/diagnastico-sobreel-uso-y-manejo-de-plaguicidas-secretaria-de- [Last access: 2020-09-06]. 